\title{
Critical Care and Emergency Medicine
}

Open Access

CASE SERIES

\section{Intravenous Sub-dissociative Dose Ketamine versus Morphine for Acute Traumatic Pain in Geriatric Patients in the Emergency De- partment: A Case Series}

\section{Sergey Motov ${ }^{1}$, Jefferson Drapkin ${ }^{1}$, Antonios Likourezos ${ }^{1}$, Peter Flom ${ }^{2}$, Catsim Fassassi ${ }^{3}$, John Marshall ${ }^{1}$ and Ronald Simon ${ }^{3}$}

${ }^{1}$ Department of Emergency Medicine, Maimonides Medical Center, USA

${ }^{2}$ Peter Flom Consulting, USA

${ }^{3}$ Department of Trauma Surgery, Maimonides Medical Center, USA

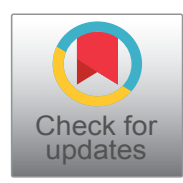

*Corresponding author: Jefferson Drapkin, Department of Emergency Medicine, Maimonides Medical Center, $96548 t h$ St. Brooklyn, NY 11219, USA, Tel: 718-283-8438

\begin{abstract}
Study objective: We compared analgesic efficacy and safety of sub-dissociative dose ketamine (SDK) to morphine for managing acute traumatic pain in geriatric emergency department (ED) patients.

Methods: A subset of geriatric patients from a randomized double-blind trial experiencing moderate to severe acute traumatic pain who received SDK at $0.3 \mathrm{mg} / \mathrm{kg}$ or morphine at $0.1 \mathrm{mg} / \mathrm{kg}$ by short intravenous infusion over 15 minutes was analyzed at $15,30,60,90$, and 120 minutes post-medication administration. Primary outcome was reduction in pain at 30 minutes. Secondary outcomes included adverse effects and rates of rescue analgesia.

Results: Twelve patients ( 5 in the SDK group and 7 in the morphine group) were eligible for analysis. The change in mean pain scores was not significantly different in SDK and morphine groups: 8.6 versus 9.1 at baseline and 5.8 versus 5.9 at 30 minutes. Patients in SDK group had a greater percentage change in pain reduction from the baseline in comparison to morphine at the 15 -minute mark $(48.8 \%$ decrease versus $30.8 \%$ decrease). In the morphine group more, patients experienced dizziness ( $57 \%$ vs. $20 \%)$ and fatigue ( $71 \%$ vs. $40 \%)$, and required more rescue analgesia at 60,90 and 120 minutes ( $14 \%$ vs. $0 \% ; 14 \%$ vs. $0 \%$, and $29 \%$ vs. $0 \%$, respectively).

Conclusion: SDK at $0.3 \mathrm{mg} / \mathrm{kg}$ over 15 minutes provided analgesia comparable to morphine for short-term treatment of acute pain with a reduced need for rescue analgesia for up to two hours and minimal rates of rates of psychoperceptual adverse effects.
\end{abstract}

\author{
Keywords \\ Ketamine, Geriatric, Analgesia, Emergency department, \\ Trauma
}

\section{Introduction}

\section{Background}

Management of acute traumatic pain in elderly patients in the Emergency Department is complicated and therefore frequently leads to suboptimal pain relief [16]. Age-related changes in drug absorption and metabolism, reduced clearance of medications, and multiple drug-drug interactions put elderly patients at significant risk of analgesic-related adverse effects and treatment failures. The administration of opioid analgesics to elderly patients frequently leads to hemodynamic instability with increased morbidity, hypotension, and respiratory and central nervous system depression $[6,7]$. Provision of effective, timely and safe analgesia for geriatric patients presenting to the Emergency Department (ED) with acute traumatic injuries results in significant reduction of patients' pain, improvement in the diagnostic workup, alleviation of anxiety and fear, and improved satisfaction of patients, their families, and staff members [7].

Data shows that elderly patients are less likely to re-

Citation: Motov S, Drapkin J, Likourezos A, Flom P, Fassassi C, et al. (2018) Intravenous Sub-dissociative Dose Ketamine versus Morphine for Acute Traumatic Pain in Geriatric Patients in the Emergency Department: A Case Series. Int J Crit Care Emerg Med 4:053. doi.org/10.23937/2474-3674/1510053

Accepted: November 10, 2018: Published: November 12, 2018

Copyright: (c) 2018 Motov S, et al. This is an open-access article distributed under the terms of the Creative Commons Attribution License, which permits unrestricted use, distribution, and reproduction in any medium, provided the original author and source are credited. 
ceive opioid analgesia or receive an appropriate dose of opioids both in the ED and on discharge in comparison to their younger counterparts [6,7]. Based on aforementioned challenges of managing geriatric pain in the ED, ED clinicians might consider exploring the utilization of non-opioid analgesics that can provide comparable or better pain relief than opioids and lower rates of serious adverse effects. One of the potential analgesics to serve this purpose is sub-dissociative dose ketamine (SDK).

\section{Importance}

Ketamine is a non-competitive N-methyl-D-aspartate (NMDA)/glutamate receptor complex antagonist that provides analgesia by reducing central sensitization, "wind-up" phenomenon, and hyperalgesia at the level of the spinal cord and central nervous system [810]. The use of ketamine in full dissociative doses for induction of anesthesia and procedural sedation in the ED frequently leads to development of emergence phenomena and cardiovascular stimulation which brings significant degree of reluctance amongst clinician to use ketamine outside of familiar indications $[9,10]$. However, when ketamine is given in sub-dissociative (low, analgesic) doses, the adverse effects are short-lived and modest in intensity, not associated with cardiovascular or respiratory compromise, and primarily involve neuro-psychiatric disturbances [11,12]. Sub-dissociative dose ketamine with a dosing range of $0.1-0.3 \mathrm{mg} /$ kg provided effective pain relief for patients with acute traumatic and non-traumatic pain, chronic non-cancer and cancer pain, and in patients with opioid-tolerant pain in pre-hospital settings and in the ED [11-15]. Two commonly utilized strategies of SDK administration in our ED include an intravenous push (IVP) dose (over 2-5 minutes) that is associated with high rates of bothersome psychoperceptual side effects (feeling of unreality and dizziness), or short infusion (SI) given over 15 minutes with reduced rates of psychoperceptual side effects and preserved analgesic efficacy [11]. To our knowledge, there is no data that evaluated SDK role in managing a variety of acute traumatic conditions in geriatric patients in the ED.

\section{Goals of this investigation}

In our study we describe a comparative change in pain score and rates of adverse effects in the subset of geriatric patients suffering from acute traumatic painful conditions who received either a sub-dissociative dose ketamine at $0.3 \mathrm{mg} / \mathrm{kg}$ via short infusion over $15 \mathrm{minu}$ tes, or morphine at $0.1 \mathrm{mg} / \mathrm{kg}$ administered over $15 \mathrm{mi}-$ nutes.

\section{Materials and Methods}

\section{Original trial}

This subset of geriatric patients suffering from acute traumatic injuries in the ED was a part of a large prospective randomized double-blind clinical trial compa- ring the analgesic efficacy and safety of intravenous SDK to intravenous morphine both administered as a short infusion (over $15 \mathrm{~min}$ ) for acute pain in elderly ED patients that was published in American Journal of Emergency Medicine [16]. This trial that included a total of 60 patients was conducted in a 711-bed community teaching hospital with an annual ED census of more than 120,000 visits. The study included patients aged 65 and older who presented to the ED with acute abdominal, flank, back, or musculoskeletal pain with an initial pain score of 5 or more on a standard 11-point (0 to 10) numeric rating scale and required opioid analgesia $[17,18]$. Exclusion criteria included allergy to morphine or ketamine, altered mental status, weight less than $40 \mathrm{~kg}$ or greater than $115 \mathrm{~kg}$, unstable vital signs (systolic blood pressure $<90$ or $>180 \mathrm{mmHg}$, pulse rate $<50$ or $>150$ beats/min, and respiration rate $<10$ or $>30$ breaths/min), and past medical history of acute head or eye injury, seizure, intracranial hypertension, severe chronic obstructive pulmonary disease, chronic pain, renal or hepatic insufficiency, alcohol or drug abuse, psychiatric illness, or recent (4 hours before) opioid use. The primary outcome of the trial included a comparative reduction of pain scores on numeric rating pain scale (NRS) between recipients of SDK and morphine at 30 minutes. The secondary outcomes consisted of a need for rescue analgesia at either 30 or 60 minutes and adverse events in each group. With respect to unique adverse effects in SDK group, we used Side Effect Rating Scale for Dissociative Anesthetics (SERSDA) and Richmond Agitation Sedation Scale (RASS) $[19,20]$. SERSDA Scale includes fatigue, dizziness, nausea, headache, feeling of unreality, changes in hearing, mood change, general discomfort, and hallucinations with severity of each graded by patients on a five-point scale, with " 0 " representing the absence of any adverse effects and " 4 " representing a severely bothersome side effect. RASS evaluates the severity of agitation and/or sedation in accordance to the nine-point scale with scores ranging from " 4 " (deeply sedated) to " 0 " (alert and calm) to " +4 " (combative). This study was approved by the Maimonides Medical Center institutional review board and registered with clinicaltrials.gov (NCT02673372). The study was conducted and reported according to the Consolidated Standards of Reporting Trials Group [21].

The results of the original trial demonstrated that SDK was as effective as morphine in relieving pain at 30 minutes but with significantly higher rates in overall adverse effects at 15 minutes post-administration $(86.7 \%$ vs. $46.7 \%)$ and at 30 minutes (73.3\% vs. $36.7 \%)$ but with reduced need for rescue analgesia at 60, 90 and $120 \mathrm{mi}-$ nutes. (6\% vs. $24 \%$ ).

The present research project is aimed to analyze a comparative change in pain scores, rates of side effect and a need for rescue analgesia in the subset of geriatric patients receiving SDK or morphine for acute traumatic pain. 


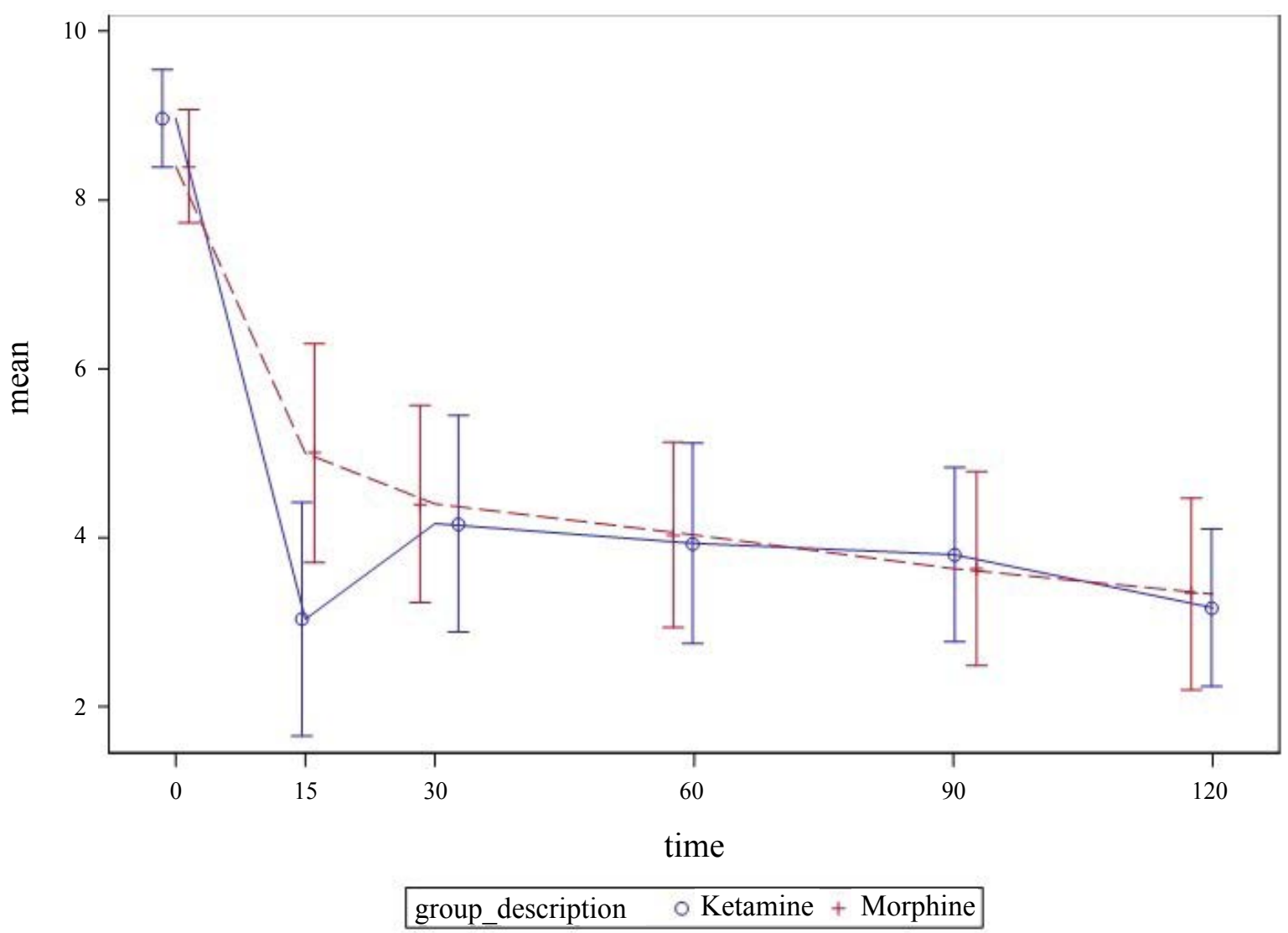

Figure 1: Reported pain numeric rating score with $95 \% \mathrm{Cl}$ bars.

Table 1: Baseline patient characteristics.

\begin{tabular}{|l|l|l|}
\hline \multicolumn{1}{|l|}{} & Ketamine & Morphine \\
\hline No of subj & 5 & 7 \\
\hline Age (mean) & 79 & 76 \\
\hline Male sex & $2(40 \%)$ & $1(14 \%)$ \\
\hline Baseline pain score & 8.6 & 9.1 \\
\hline Baseline vitals & & \\
\hline HR & 81.2 & 80.1 \\
\hline BP Sys & 149.4 & 149.9 \\
\hline BP Diast & 69.6 & 74.6 \\
\hline RR & 16.8 & 23.8 \\
\hline O & 97.4 & 96 \\
\hline Type of trauma & & \\
\hline Pelvic Fx & $1(20)$ & $5(71)$ \\
\hline Radius Fx & $1(20)$ & $0(0)$ \\
\hline Tibia Fx & $1(20)$ & $0(0)$ \\
\hline Femur Fx & $1(20)$ & $1(14)$ \\
\hline Ulnar Fx & $1(20)$ & $0(0)$ \\
\hline Rib Fx & $0(0)$ & $1(14)$ \\
\hline & & \\
\hline
\end{tabular}

\section{Results}

Twelve patients ( 5 in SDK group and 7 in morphine group) were eligible for subgroup-analysis. The patients' mean age was 79 and 76 years with male patients comprising $40 \%$ and $14 \%$ in each group respectively. There were no differences between the groups in terms of baseline vital signs and pain scores. However, more patients in the morphine group had acute traumatic pelvic fracture (71\%) as a source of pain (Table 1 ).

All patients showed significant reductions in mean
Table 2: Pain trends.

\begin{tabular}{|l|l|l|}
\hline Pain at each time point & Ketamine & Morphine \\
\hline Baseline & 8.6 & 9.1 \\
\hline $15 \mathrm{~min}$ & 4.4 & 6.3 \\
\hline $30 \mathrm{~min}$ & 5.8 & 5.9 \\
\hline $60 \mathrm{~min}$ & 5.2 & 4.7 \\
\hline $90 \mathrm{~min}$ & 5.6 & 4.6 \\
\hline $120 \mathrm{~min}$ & 4.2 & 3.6 \\
\hline Full resolution of pain & & \\
\hline $15 \mathrm{~min}$ & $1(20)$ & $1(14)$ \\
\hline $30 \mathrm{~min}$ & $1(20)$ & $0(0)$ \\
\hline $60 \mathrm{~min}$ & $1(20)$ & $1(14)$ \\
\hline $90 \mathrm{~min}$ & $0(0)$ & $1(14)$ \\
\hline $120 \mathrm{~min}$ & $1(20)$ & $1(14)$ \\
\hline Reduction NRS 3+ & & \\
\hline $15 \mathrm{~min}$ & $4(80)$ & $3(43)$ \\
\hline $30 \mathrm{~min}$ & $3(60)$ & $4(57)$ \\
\hline $60 \mathrm{~min}$ & $4(80)$ & $4(57)$ \\
\hline $90 \mathrm{~min}$ & $3(60)$ & $5(71)$ \\
\hline $120 \mathrm{~min}$ & $3(60)$ & $5(71)$ \\
\hline Rescue analgesia given & & \\
\hline $15 \mathrm{~min}$ & $0(0)$ & $0(0)$ \\
\hline $30 \mathrm{~min}$ & $0(0)$ & $0(0)$ \\
\hline $60 \mathrm{~min}$ & $0(0)$ & $1(14)$ \\
\hline $90 \mathrm{~min}$ & $0(0)$ & $1(14)$ \\
\hline $120 \mathrm{~min}$ & $0(0)$ & $2(29)$ \\
\hline & & \\
\hline & & \\
\hline
\end{tabular}

pain score at 15-120 minutes in comparison to baseline (Table 2). At 15-minutes, the SDK group demonstrated a greater percentage change in pain score from the baseline in comparison to morphine $(48.8 \%$ decrease versus 
$30.8 \%$ decrease). At 30 minutes, the percentage change in pain score was essentially the same $(32.6 \%$ versus $35.2 \%)$. The box plots of the difference show a similar pattern of central tendency and dispersion. A comparison of the pain scores over time demonstrates similar percentage change in a pain score between two groups with exception of the 15-minute time frame where the SDK group had a greater percentage change in mean pain score (Figure 1). In addition, more patients in the SDK group had complete resolution of pain at 30 minutes ( $20 \%$ vs. $0 \%)$.
None of the patients in each group required rescue analgesia at 30 minutes. However, at 60-120 minutes, more patients in the morphine group required rescue analgesia (4 patients vs. 0 patients) with percent difference of $14 \%, 14 \%$ and $29 \%$ respectively (Table 2 ).

With respect to rates and severity of adverse effects in the SDK group on the SERSDA scale, 2 patients experienced side effects (dizziness, fatigue, and change in vision) that were weak-to-modest in intensity. One patient experienced a bothersome headache at $15 \mathrm{mi}-$ nutes (Table 3 ) and one patient reporting moderate se-

Table 3: Severity of SERSDA.

\begin{tabular}{|c|c|c|c|c|c|c|}
\hline \multicolumn{7}{|l|}{ Level of severity } \\
\hline Adverse effect & Time point & 0 - No Change & 1 - Weak & 2 - Modest & 3 - Bothersome & 4 - Very Bothersome \\
\hline \multirow{5}{*}{ Dizziness } & $15 \mathrm{~min}$ & 4 & - & 1 & - & - \\
\hline & $30 \mathrm{~min}$ & 5 & - & - & - & - \\
\hline & $60 \mathrm{~min}$ & 5 & - & - & - & - \\
\hline & $90 \mathrm{~min}$ & 5 & - & - & - & - \\
\hline & $120 \mathrm{~min}$ & 5 & - & - & - & - \\
\hline \multirow[t]{5}{*}{ Feeling unreality } & $15 \mathrm{~min}$ & 3 & 1 & 1 & - & - \\
\hline & $30 \mathrm{~min}$ & 5 & - & - & - & - \\
\hline & $60 \mathrm{~min}$ & 5 & - & - & - & - \\
\hline & $90 \mathrm{~min}$ & 5 & - & - & - & - \\
\hline & $120 \mathrm{~min}$ & 5 & - & - & - & - \\
\hline \multirow[t]{5}{*}{ Fatigue } & $15 \mathrm{~min}$ & 3 & - & 2 & - & - \\
\hline & $30 \mathrm{~min}$ & 5 & - & - & - & - \\
\hline & $60 \mathrm{~min}$ & 5 & - & - & - & - \\
\hline & $90 \mathrm{~min}$ & 5 & - & - & - & - \\
\hline & $120 \mathrm{~min}$ & 5 & - & - & - & - \\
\hline \multirow[t]{5}{*}{ Change in hearing } & $15 \mathrm{~min}$ & 5 & - & - & - & - \\
\hline & $30 \mathrm{~min}$ & 5 & - & - & - & - \\
\hline & $60 \mathrm{~min}$ & 5 & - & - & - & - \\
\hline & $90 \mathrm{~min}$ & 5 & - & - & - & - \\
\hline & $120 \mathrm{~min}$ & 5 & - & - & - & - \\
\hline \multirow[t]{5}{*}{ Headache } & $15 \mathrm{~min}$ & 4 & - & - & - & 1 \\
\hline & $30 \mathrm{~min}$ & 4 & 1 & - & - & - \\
\hline & $60 \mathrm{~min}$ & 5 & - & - & - & - \\
\hline & $90 \mathrm{~min}$ & 5 & - & - & - & - \\
\hline & $120 \mathrm{~min}$ & 5 & - & - & - & - \\
\hline \multirow[t]{5}{*}{ Change in vision } & $15 \mathrm{~min}$ & 4 & - & 1 & - & - \\
\hline & $30 \mathrm{~min}$ & 4 & 1 & & - & - \\
\hline & $60 \mathrm{~min}$ & 5 & - & - & - & - \\
\hline & $90 \mathrm{~min}$ & 5 & - & - & - & - \\
\hline & $120 \mathrm{~min}$ & 5 & - & - & - & - \\
\hline \multirow[t]{5}{*}{ General discomfort } & $15 \min$ & 4 & - & 1 & - & - \\
\hline & $30 \mathrm{~min}$ & 4 & 1 & - & - & - \\
\hline & $60 \mathrm{~min}$ & 5 & - & - & - & - \\
\hline & $90 \mathrm{~min}$ & 5 & - & - & - & - \\
\hline & $120 \mathrm{~min}$ & 5 & - & - & - & - \\
\hline \multirow[t]{5}{*}{ Mood change } & $15 \mathrm{~min}$ & 5 & - & - & - & - \\
\hline & $30 \mathrm{~min}$ & 5 & - & - & - & - \\
\hline & $60 \mathrm{~min}$ & 5 & - & - & - & - \\
\hline & $90 \mathrm{~min}$ & 5 & - & - & - & - \\
\hline & $120 \mathrm{~min}$ & 5 & - & - & - & - \\
\hline \multirow[t]{5}{*}{ Hallucination } & $15 \mathrm{~min}$ & 5 & - & - & - & - \\
\hline & $30 \mathrm{~min}$ & 5 & - & - & - & - \\
\hline & $60 \mathrm{~min}$ & 5 & - & - & - & - \\
\hline & $90 \mathrm{~min}$ & 5 & - & - & - & - \\
\hline & $120 \mathrm{~min}$ & 5 & - & - & - & - \\
\hline
\end{tabular}




\begin{tabular}{|l|l|l|l|l|l|l|}
\hline Nausea & $15 \min$ & 5 & - & - & - & - \\
\hline & $30 \min$ & 5 & - & - & - & - \\
\hline & $60 \min$ & 5 & - & - & - & - \\
\hline & $90 \min$ & 5 & - & - & - & - \\
\hline
\end{tabular}

Table 4: Patients reporting agitation or sedation according to RASS.

\begin{tabular}{|c|c|c|c|c|c|c|c|c|c|c|}
\hline \multirow[b]{2}{*}{$\begin{array}{l}\text { Time } \\
\text { point }\end{array}$} & \multicolumn{5}{|c|}{ Level of sedation } & \multicolumn{4}{|l|}{ No effect } & \multirow{2}{*}{$\begin{array}{l}\text { Level of } \\
\text { agitation } \\
\text { +4 } \\
\text { Combative }\end{array}$} \\
\hline & $\begin{array}{l}-5 \\
\text { Unarousable }\end{array}$ & $\begin{array}{l}-4 \text { Deep } \\
\text { sedation }\end{array}$ & $\begin{array}{l}\text {-3 Moderate } \\
\text { sedation }\end{array}$ & $\begin{array}{l}\text {-2 Light } \\
\text { sedation }\end{array}$ & -1 Drowsy & $\begin{array}{l}0 \text { Alert \& } \\
\text { calm }\end{array}$ & $\begin{array}{l}\text { +1 } \\
\text { Restless }\end{array}$ & $\begin{array}{l}\text { +2 } \\
\text { Agitated }\end{array}$ & $\begin{array}{l}\text { +3 Very } \\
\text { agitated }\end{array}$ & \\
\hline $15 \mathrm{~min}$ & - & - & 1 & - & - & 3 & 1 & - & - & - \\
\hline $30 \mathrm{~min}$ & - & - & & - & - & 5 & & - & - & - \\
\hline $60 \mathrm{~min}$ & - & - & & - & - & 5 & & - & - & - \\
\hline $90 \min$ & - & - & & - & - & 5 & & - & - & - \\
\hline $120 \mathrm{~min}$ & - & - & & - & - & 5 & & - & - & - \\
\hline
\end{tabular}

Table 5: Rates of adverse effects \& intervention.

Most common adverse effect

\begin{tabular}{|l|l|l|l|l|l|l|l|l|}
\hline & Dizziness & Discomfort & \multicolumn{2}{l|}{ Fatigue } & \multicolumn{2}{l|}{ Change in vision } \\
\hline Time & Ketamine & Morphine & Ketamine & Morphine & Ketamine & Morphine & Ketamine & Morphine \\
\hline $15 \mathrm{~min}$ & 1 & 1 & 1 & 0 & 2 & 1 & 1 & 1 \\
\hline $30 \mathrm{~min}$ & 0 & 1 & 1 & 0 & 0 & 1 & 1 & 0 \\
\hline $60 \mathrm{~min}$ & 0 & 2 & 0 & 1 & 0 & 1 & 0 & 0 \\
\hline $90 \mathrm{~min}$ & 0 & 0 & 0 & 1 & 0 & 1 & 0 & 0 \\
\hline $120 \mathrm{~min}$ & 0 & 0 & 0 & 0 & 0 & 1 & 0 & 0 \\
\hline
\end{tabular}

Table 6: Report of any intervention.

\begin{tabular}{|l|l|l|}
\hline Intervention & Ketamine & Morphine \\
\hline $15 \mathrm{~min}_{2}$ & $1(20)$ & $0(0)$ \\
\hline
\end{tabular}

dation according to the RASS scale (Table 4). By comparing most common adverse effect between two groups, more patients in morphine group experienced dizziness (57\% vs. $20 \%$ ) and fatigue (71\% vs. $40 \%$ ) (Table 5).

No serious or life-threatening adverse events occurred in either group. There were no changes in vital signs that were clinically concerning. Most adverse effects were transient and did not require treatment, with exception of one patient in the SDK group who required supplemental oxygen for correction of brief desaturation at 15 minutes (Table 6).

\section{Limitations}

The small number of geriatric patients suffering from acute traumatic injuries in this case series does not allow us to make any definitive conclusion on the true analgesic efficacy and safety of SDK. As these patients had only acute musculoskeletal injury, it limits our ability to extrapolate the results of our analysis to other traumatic injuries.

\section{Discussion}

SDK remains an attractive analgesic modality for patients presenting to the ED with a variety of acute traumatic and non-traumatic painful conditions. However, the published data on its safety and efficacy is limited to patients younger than 65 years of age. Possible reasons for limited utilization of SDK in geriatric ED patients in- clude a lack of experience, reluctance of ketamine utilization due to emergence phenomenon, hyperdynamic vital signs, increased intracranial and intraocular pressure, administrative and regulatory concerns as well as off-label use.

The results of our subset analysis of geriatric patients presenting to the ED with acute traumatic musculoskeletal pain and receiving SDK at $0.3 \mathrm{mg} / \mathrm{kg}$ dose over 15 minutes demonstrated analgesic efficacy comparable to morphine for up to 120 minutes, greater improvement in pain score at 15 minutes, and diminished need for rescue analgesia up to 120 minutes post-administration. In addition, SDK group had less patients experiencing dizziness and fatigue, and unique to dissociative anesthetic, small overall percentage of patients (21\%) experiencing psychoperceptual side effects of weak to-moderate intensity. These findings are consistent with the findings of the original GERIKET trial, where more patient in the SDK group had larger decrease in pain scores at $15 \mathrm{mi}-$ nutes.

We believe that there is great need for further prospective randomized trials that will compare different dosing regimens and duration of infusions to find an optimal dosing regimen with a good balance of analgesic efficacy and rates of side effects.

In conclusion, our sub-group analysis of geriatric trauma patients demonstrated that sub-dissociative dose intravenous ketamine administered at $0.3 \mathrm{mg} /$ kg over 15 min provides analgesic efficacy comparable to intravenous morphine for short-term (up to $120 \mathrm{mi}$ nutes) treatment of acute moderate-to- severe pain in 
geriatric ED patients with minimal rates of weak-to-modest intensity psychoperceptual adverse effects.

\section{Disclosure}

\section{Funding support}

None.

\section{Conflicts of interest}

All authors have completed and submitted the ICMJE Form for Disclosure of Potential Conflicts of Interest. The authors have no independent disclosures or conflicts of interest.

\section{Authorship}

\section{Author contributions}

\section{Study concept and design: Motov}

Acquisition, analysis, or interpretation of data: All authors

\section{Statistical analysis: Likourezos, Flom}

Drafting of the manuscript: Motov, Drapkin, Fassassi

Critical revision of the manuscript for important intellectual content: Motov, Marshall, Simon

Study supervision: Motov, Likourezos.

\section{References}

1. Long J, Shenvi C (2017) Acute pain and procedural sedation in older adults. In: Strayer R, Motov S, Nelson L, Management of pain and procedural sedation in acute care.

2. Gibson SJ (2003) Pain and ageing: A comparison of the pain experience over the adult life span. Prog Pain Res Manage 24: 767-790.

3. American geriatrics society panel on the pharmacological management of persistent pain in older persons (2009) Pharmacological management of persistent pain in older persons. J Am Geriatr Soc 57: 1331-1346.

4. Dunn KM, Saunders KW, Rutter CM, Banta-Green CJ, Merrill JO, et al. (2010) Opioid prescriptions for chronic pain and overdose: A cohort study. Ann Intern Med 152: 85-92.

5. Platts-Mills TF, Esserman DA, Brown DL, Bortsov AV, Sloane PD, et al. (2012) Older US emergency department patients are less likely to receive pain medication than younger patients: Results from a national survey. Ann Emerg Med 60: 199-206.

6. Terrell KM, Hui SL, Castelluccio P, Kroenke K, McGrath $\mathrm{RB}$, et al. (2010) Analgesic prescribing for patients who are discharged from an emergency department. Pain Med 11: 1072-1077.

7. Herr K, Titler M (2009) Acute pain assessment and pharmacological management practices for the older adult with a hip fracture: Review of ED trends. J Emerg Nurs 35: 312-320.
8. Gao M, Rejaei D, Liu H (2016) Ketamine use in current clinical practice. Acta Pharmacol Sin 37: 865-872.

9. Kurdi MS, Theerth KA, Deva RS (2014) Ketamine: Current applications in anesthesia, pain, and critical care. Anesth Essays Res 8: 283-290.

10. Tziavrangos E, Schug SA (2008) Clinical pharmacology: Other adjuvants. In: Macyntyre P, Rowbotham D, Walker S, Clinical pain management: Acute pain. ( $2^{\text {nd }}$ edn), Hodder \& Stoughton limited, 98-101.

11. Motov S, Mai M, Pushkar I, Likourezos A, Drapkin J, et al. (2017) A prospective randomized, double-dummy trial comparing intravenous push dose of low dose ketamine to short infusion of low dose ketamine for treatment of moderate to severe pain in the emergency department. Am J Emerg Med 35: 1095-1100.

12. Ahern TL, Herring AA, Anderson ES, Madia VA, Fahimi J, et al. (2015) The first 500: Initial experience with widespread use of low-dose ketamine for acute pain management in the ED. Am J Emerg Med 33: 197-201.

13. Beaudoin FL, Lin C, Guan W, Merchant RC (2014) Low-dose ketamine improves pain relief in patients receiving intravenous opioids for acute pain in the emergency department: Results of a randomized, double-blind, clinical trial. Acad Emerg Med 21: 1193-1120.

14. Motov S, Rockoff B, Cohen V, Pushkar I, Likourezos A, et al. (2015) Intravenous subdissociative-dose ketamine versus morphine for analgesia in the emergency department: A randomized controlled trial. Ann Emerg Med 66: 222-229.

15. Goltser A, Soleyman-Zomalan E, Kresch F, Motov S (2015) Short (low-dose) ketamine infusion for managing acute pain in the ED: Case-report series. Am J Emerg Med 33: 601.e5-601.e7.

16. Motov S, Mann S, Drapkin J, Butt M, Likourezos A (2018) Intravenous subdissociative-dose ketamine versus morphine for acute geriatric pain in the emergency department: A randomized controlled trial S0735-S6757: 30407-30408.

17. Bijur PE, Latimer CT, Gallagher EJ (2003) Validation of a verbally administered numerical rating scale of acute pain for use in the emergency department. Acad Emerg Med 10: 390-392.

18. Holdgate A, Asha S, Craig J, Thompson J (2003) Comparison of a verbal numeric rating scale with the visual analogue scale for the measurement of acute pain. Emerg Med 15: 441-446.

19. Eide K, Stubhaug A, Oye I, Breivik H (1995) Continuous subcutaneous administration of the $\mathrm{N}$-methyl-D-aspartic acid (NMDA) receptor antagonist ketamine in the treatment of post-herpetic neuralgia. Pain 61: 221-228.

20. Ely EW, Truman B, Shintani A, Thomason JW, Wheeler AP, et al. (2003) Monitoring sedation status over time in ICU patients: Reliability and validity of the Richmond Agitation-Sedation Scale (RASS). JAMA 289: 2983-2991.

21. Schulz KF, Altman DG, Moher D, the Consort Group (2010) CONSORT 2010 statement: Updated guidelines for reporting parallel group randomized trials. Trials 11: 30-32. 